\title{
ESTUDIOS
}

\section{Nueva Refutación del Cosmos}

Droctulft, el guerrero bárbaro, se convierte a la causa de Ravena al contemplar la ciudad imago mundi, la urbe orbe, esa fábrica armonica y razonada, erigida a imagen y semejanza del Empíreo. Droctulft desecha su mundo de inextricables selvas, sus ídolos feroces que encarnan la turbamulta de instintivos apetitos, el caótico combate regido por crueles e insondables potencias; es iluminado por la seducción del orden, de ese organismo que la simetría gobierna, por esa mecánica de la concordancia que parece invalidar su primitivismo, su pasado cenagoso, su ligazón irracional con lo salvaje.

La ciudad concierta la semejanza y la diferencia, responde a un principio de conexión racional que presupone un designio consonante por encima de las voluntades individuales; lo engloba todo y todo lo compone según ese diseño que predice la presencia de una inteligencia suprema. La norma urbana parece prefigurar el concierto cósmico.

Droctulft es la antítesis compensadora de la cautiva inglesa que trece siglos después, trece siglos de civilización letrada, de acumulada sabiduría libresca, elige convivir con el indio, aposentarse en la inmensidad de la pampa; opta por la barbarie, por borrar lo escrito, por la tabla rasa. Vuelve al caos, a la crasa realidad de lo corporal, de lo terrestre no desvirtuado por una codifi cacion ilusoria, no interferido por las leyes de la civitas, impropias, impotentes para desentrañar el inescrutable sentido del universo.

Defecto y exceso se contrapesan, arrebatan, producen un frenesí equiparable. En la Historia del guerrero y de la cautiva, la entrada en y la salida de la racionalidad occidental constituyen enajenamientos que la perturban fundamentalmente, sendos escándalos de la razón, el anverso y el reverso de una misma moneda, complementarios que se acoplan para inscribir, por encima de la lejanía temporal y espacial, por encima de nuestras dimensiones, de nuestros imperativos lógicos, una sola historia que nos es en definitiva ininteligible.

Droctulft es el incivilizado, hombre feral y rústico, que se deslumbra ante esa planificada materializacion del logos totalitario: la metropoli, la ciudad madre, el centro del imperio, vision geométrica de un espacio sistematizado. La infinita y simultánea heterogeneidad de lo real aparece, reducida, por lo menos en ese ingenioso recinto, a norma escrita en piedra o sea a decalogo perdurable. El asombro bárbaro ante la diestra arquitectura se sitúa en la antípoda de la desilusión de los inmortales frente a la falacia de toda fabricación humana. La Ciudad de los Inmortales, antes rica en bellas construcciones equilibradamente repartidas: arcos, foros, palacios, templos, anfiteatros, esplendores de granito y mármol, la otrora resplandeciente ciudad, espejo del cosmos, como lo fueron las epopeyas de Homero, ha sido asolada y derribada por sus mismos moradores. Con sus ruinas edificaron ese laberinto y el palacio al que se accede, más intrincado aún que la selva de Droctulft. Parece anterior a los hombres; interminablemente atroz e insensato, es templo de los dioses 
irracionales que comandan el mundo, de los impenetrables de quienes nada sabemos salvo que son distintos del hombre. El palacio precede, el palacio es la desatinada ciudad donde impera el caos, la desatinada ciudad simboliza el universo.

El bárbaro se pasma ante un cosmos en escala humana; el sabio--El inmortal--lo desecha porque es vana apariencia, mero simulacro de conocimiento; destruye esa ilusión, construye un irrecuperable, un ilegible absurdo y retorna al comienzo, a la condición bestial del troglodita, a la vida latente, al estado contemplativo donde imaginar y sentir son los consuelos que quedan ante la imposibilidad de comprender.

Droctulft pasa de la ceguera a una iluminación aparente, encendida por la supuesta potestad de la ciudad terrestre. El tribuno Marco Flaminio Rufo, creyendo en su ingenuidad de hombre mortal que la Ciudad celeste será el canon perfecto del cual Roma, ombligo del mundo, es la mejor réplica, atraviesa el ámbito ambiguo, la desconcertante región de tenebrosos laberintos entramados, desemboca en la arquitectura sin proporción ni propósito, para asumir por fin la evidencia del puro dislate, de la arbitrariedad sin destino, sin sentido, sin término. Por un territorio intermedio, pasa de la abstraccion del cosmos asentado sobre la superficie de la realidad a la basamental profundidad del caos.

Marco Flaminio Rufo rehace la peripècia del inmortal Homero quien después de haber idealizado, es decir estilizado, la conquista de Troya, dotándola de talla épica, cantó la guerra entre ranas y ratones, como un dios que bajase del cosmos al caos, como un clarividente que rebajándose retornase a la confusión del comienzo.

El laberinto humano es una transición: laberintos espaciales como la casa de Asterion o la de Abenjacán el Bojari, como el broncineo del rey de Babilonia o el de la biblioteca de Babel, laberintos de escaleras, galerías, pabellones, laberintos espejados, laberinto cuadrangular del Tetragrámaton o laberinto lineal que Scharlach propone a Lënnrot en La muerte y la brújula, laberintos temporales, textuales, discursivos, inscriptos criptográficamente en la urdimbre de una historia, laberintos eventuales, fácticos, laberintos progresivos como el del libro de Ts'ui Pên o retrospectivos como el de la novela regresiva, ramificada de Herbert Quain, o circulares como el drama en verso Los enemigos de Jaromir Hladík, laberintos cosmológicos como Tlön. Todos son artificios concebidos por hombres para desorientar a otros hombres, destinados a que los hombres los descifren. Combinan lo caotico con lo regular, implican uña proporciún de cao que no anula la simetría. Perturban pero no rompen la forma inteligible, es decir la concatenación racional, la causalidad convenida, la verosimilitud acordada. Representan una arquitectura conciliable con las estructuras de la mente humana, una confusión recuperable por el orden estatuido; son todavía logomaquias, antropomorfismos logocéntricos. Provocan un desconcierto que proviene del alto grado de novedad, de incertidumbre, pero no excluyen lo conocido y cognoscible. No están del todo exentos de la fun cionalidad propia de la ciudad terrestre, donde cada forma, cada disposición responder a su oficio. No están despojados de razón numérica (el nueve preside la distribución del laberinto que da acceso a la Ciudad de los Inmortales, el cinco comanda la de la biblioteca de Babel). La repetición permite establecer especies, géneros, categorias, puede ser codificada, formalizada, descripta, denotada, con- 
ceptualizada, asimilada al entendimiento del hombre. Está sujeta a una regularidad no inmediatamente perceptible pero sí a través de la experiencia, de los aciertos, de los yerros y de su posterior intelección.

Los laberintos humanos pueden ser interpretados. No así los laberintos naturales, como la escritura de Dios cifrada en las manchas del jaguar 1 ". .las manchas de la piel son un mapa de las incorruptibles constelaciones"-dice Borges en Tres versiones de Judas), mapamundi cuyo orden y configuración repiten los del universo. Pero esa sentencia divina es para los mortales indescrifable, tanto como cualquier flor cuya imposible comprensión nos permitiría saber qué somos y qué es el mundo. El intrincadísimo laberinto del rey de Babilonia no compite ni en complejidad ni en sutileza con el inextricable desierto. Para qué construir laberintos, si el universo ya lo es. No existe laberinto más pasmoso y más confuso, no existe laberinto más inescrutable que el de la realidad natural: la salida, según Borges, nos está inapelablemente oculta, irremediablemente vedada.

Tal es el enrevesado mensaje, el postrero que los inmortales signaron al levantar el dislate, el total desatino, la disparatada ciudad. Ese mensaje dice la insuperable imposibilidad de comprender el universo que, si está regido por alguna norma, ella escapa a los hombres. Los designios supremos son inaccesibles; los hemos suplantado con espectaculares sistemas especulativos que creemos espejo de la realidad. Ellos nos autosatisfacen aportándonos una ilusión de conocimiento pertinente. Instauran una cosmología que prejuzga la falaz equivalencia entre razón, verdad y realidad como si responder a las categorias del entendimiento fuese una exigencia no sólo nuestra sino del objeto de conocimiento, fuese un criterio de verdad extensible a la realidad externa. El mensaje de los inmortales restaura el definitivo imperio del caos, del absurdo, del sin sentido infranqueable al cual estamos por nuestras limitaciones condenados.

Presa de una irrevocable tendencia a la diversidad, la horripilante, la nefasta Ciudad es irreducible a norma humana. Nada en ella es operativo, nada en ella es útil o utensilio, nada se supedita a una función. Equivale a pesadilla, confusión de formas, subversión total de categorías. Es como un desparramo de signos desiguales que desbaratan toda linealidad, que desquician toda ilación discursiva. Escritura demasiado heterogénea, no puede interpretarse ni literal ni simbólicamente. $O$ si algo simboliza es la negación del símbolo. El mensaje se basa en un código desconocido por el destinatario. El mensaje limitrofe dice la imposibilidad de comunicar algo significativo.

La Ciudad equivale a universo. Es anterior a los hombres; no pudo haber sido concebida por una inteligencia humana. Edificada por inmortales, si fue morada divina lo fue de dioses dementes que la abandonaron. Verla produce menos miedo que pensarla. No es la visión la que aterra sino la imposibilidad de discernimiento. No es la experiencia sensible la que desespera sino sus consecuencias reflexivas. No es la percepción la que espantá sino la idea de una realidad que invalida toda idea.

En la ciudad de los mortales rige la armonía i es microcosmo reflejo del supuesto macrocosmo. La Ciudad de los Inmortales fue erigida para restablecer la verdadera 
equivalencia entre urbe y orbe, es decir para restablecer la continuidad de la entropía universal. La desproporcionada ciudad, incompatible con nuestros arbitrios, rigores y obstinaciones, es la reversión paródica de la ciudad legible. Implica la vuelta al estado inicial, la vuelta a la ilegibilidad natural. Ultimo símbolo transigido por los inmortales, texto que invalida todos los otros, significa la insignificancia de los lenguajes humanos.

Dos mentes distintas, como la de un tribuno romano y un miserable troglodita, participan de universos diferentes. El nuestro es una combinación de nuestra mente, la cual nos impone percibirlo y concebirlo según su peculiar tesitura. Dos mentes de distinta estructura tendrían distinta visión y distinta intelección de un mismo mundo; idearian distintos objetos, porque el objeto es una manera abstracta de recortar la continuidad de lo real (totalidad impensable y por tanto inoperante) para manipular segmentos designables y definibles según determinados efectos. Los objetos son, como los hrönir de Tlön, producidos por los fines a los que deben corresponder. Los objetos son productos del deseo, deseo objetivado o deseo objetual. Son productos de una onirogénesis, semejante a la del soñador que en Las ruinas circulares interpola su soñado en la realidad, para descubrir a la postre que ambos, generador y generado, son intercambiables. Ambos, sujeto y objeto, son igualmente ilusorios; ambos, en paridad, participan de la misma fantasmagoría; con identidad y entidad espectrales, resultan imágenes quiméricas de un mismo juego de reflejos irreales.

Nuestro lenguaje tiene que hacer pasar la ubicua y simultánea heterogeneidad de lo real por la sucesión lineal. Abunda en sustantivos que designan objetos, en sustantivos que son los segmentos identificables, los recortes convenidos, los detenimientos, los refugios semánticos, los aseguradores del orden estatuido. Los sustantivos son los sustentáculos reguladores de un universo de sentido postulado según sus exigencias internas. Los sustantivos son los guardianes del sistema, los agentes del totalitarismo logocéntrico.

Con nuestro lenguaje sucesivo y sustantivado, la realidad es indecible, la indivisa y cambiante totalidad es inefable. Más pertinente sería el lenguaje que imagina Marco Flaminio Rufo, apropiado a un mundo sin el tiempo y la memoria humanos, un lenguaje que ignore como el de Tlön los sustantivos, un lenguaje de verbos impersonales, no conjugados por el sujeto, y de indeclinables adjetivos, sin la imposición de concordancia, o sea no adjudicables al objeto, una acción continua sin sujeto y sin objeto. Acceder a este lenguaje, es decir al mundo, equivale a entrar en la inmortalidad, entrar en un infinito anulador de toda separación, anulador de toda identidad individual, de todo particularismo. Este lenguaje conjetura la existencia de un solo sujeto indivisible: el universo.

Y si no se puede decir el mundo exterior al pensamiento, queda el consuelo del lenguaje empedernido, resignadamente idealista de Tlön donde también faltan los sustantivos, denominadores comunes de lo categorial, de lo invariable, de lo prototípico, o se construyen por acumulación de adjetivos. Negada la existencia del espacio, el sistema de composición léxica es allí el más apto para nombrar lo móvil, lo 
mudable, lo sumergido en la corriente temporal. En la lengua de Tlön los objetos no son tales; son momentáneas asociaciones, convergencia de sensaciones, de fenómenos fugaces que se encuentran en la ocasional encrucijada de un vocablo. Esta combinatoria permite concertar infinitos nombres con o sin correlato objetivo. No poseen valor referencial, responden exclusivamente a necesidades poéticas. La lengua se desembaraza por completo de las restricciones de lo real empírico, como si se propusiera poner planetariamente en práctica el creacionismo de Huidobro: la autosuficiencia, autorreflexión y autorreferencia del objeto poético.

En Tlön, un poema puede estar integrado por una sola y multitudinaria palabra, amalgamadora de profusos adjetivos. Si fuesen incontables, esa palabra diría el universo, esa palabra correspondería a la escritura de Dios. Así discurre Tzinacán, mago de la pirámide de Qaholom: si en los lenguajes humanos, por extensiva concatenación causal, toda proposición implica el universo (tigre presupone la escala zoológica, el mundo vegetal que lo alimenta y el mineral que nutre la flora), un dios necesitará de una sola palabra para contener expresa y simultáneamente el universo. Cuando decimos universo, decimos sombra o simulacro de esa totalidad por la insignificante significación que somos capaces de otorgarle.

La implicación universal y la inefabilidad son también atributos de la Ciudad monstruosa. Aunque situada en el centro de un desierto ignoto, ella contamina, según el ineludible encadenamiento de causas y efectos, todo tiempo, todo espacio, por más remotos que fuesen. Dada su condición divina, por ser causa primera, causa de causas, invalida el principio de razón suficiente. Si imaginamos la realidad como una ininterrumpida concatenación causal, los precedentes, cuanto más pretéritos, más deberán influir en lo sucedido y en lo por suceder. Admitido que la realidad es una e indivisa, cualquier suceso, por más banal, tiene imprevisibles consecuencias, condiciona todos los demás. A menos que aceptemos causalidades autónomas, lo cual contraviene la noción de cosmos unificador sujeto a principios uniformes, noción que Borges corroe con sus disolventes paradojicos.

En La otra muerte lucubra en torno de la revocabilidad del pasado. Nadie puede modificar lo ocurrido, quizá su imagen pero no los hechos. Tan dilatada, tan intrincada,tan entrañable es la concatenación causal que no puede anularse ningún hecho remoto, por más insignificante que fuera, sin invalidar el presente: "Modificar el pasado no es modificar un solo hecho; es anular sus consecuencias, que tienden a ser infinitas. Dicho sea con otras palabras ; es crear dos historias universales."

Si tan espesa y tan intima es la trama causal, todos los hechos que puedan ocurrir a un hombre han sido predeterminados por él. La casualidad se vuelve causalidad. Y todo suceso personal résulta de una sabida o ignorada elección, incluso la muerte y las desdichas. Esta teleologia individual, aventura Borges, presupone un orden secreto donde hasta el pensamiento más fugaz respondería a un dibujo invisible, a una configuración que todo lo involucra. Lo más nimio puede coronar o inaugurar una forma imprevisible. No hay cosa que no pueda ser simiente de un infierno. Un oscuro prestamista londinense muere creyendo vana su vida e ignora que su justificación es haber inspirado a un cliente ocasional el personaje de Shylock. 
Virgilio supone, en su Egloga cuarta, augurar el nacimiento de un hombre y revela el de Cristo. Lutero, traductor de la Biblia, funda una estirpe que intentará destruirla para siempre.

Tamaña determinación causal invalida toda iniciativa, eslabonándola a una cadena irremisible. Benjamín Otálora, compadrito convertido por una muerte a cuchillo en rastreador y contrabandista, ambiciona suplantar a su jefe Azevedo Bandeira; codicia su mujer, su apero y su caballo. Cuando parece conseguir lo querido, descubre que es víctima de una maquinación de Bandeira, quien le permitió la arrogancia, el amor, el mando porque ya lo había sentenciado, ya lo daba por muerto.

Aceptada la fatalidad de esta trabazón, todo acto es justo por indeclinable; todo destino resulta ineluctable porque está forzosamente prescripto. Entonces toda valoración moral se torna ociosa, toda axiología queda anulada. No habría méritos ni desméritos. Por eso los inmortales se perfeccionan en la tolerancia y el desdén. $O$ las virtudes y las infamias están, como las cifras pares e impares en los juegos de azar, sujetas a un secreto principio de compensación. Concebir el universo como sistema de precisas compensaciones invalida toda piedad. Los virtuosos y los infames resultan igualmente necesarios, están igualmente predestinados por la adjudicación de un destino propicio o adverso. Así lucubra Broges hipotéticamente, así zapa la firmeza de nuestros consensos morales, asi trastorna la seguridad semántica de nuestros axiomas éticos. Confrontando y combinando distintas concepciones, extrema la deducción, la lleva a sus últimas consecuencias lógicas. Paradójicamente, la hipertrofia racional desemboca en la atrofia moral.

Sería igualmente lícito buscar la purificación por el bien que por el mal. 0 extremar el mal es, como ocurre con Judas, incrementar su contrario. La traición de Judas está prefijada en la economía de la redención. Judas es el reflejo invertido de Jesús. Eligió las culpas no morigeradas por ninguna virtud, eligió la delación por humildad y ascetismo, eligió la reprobación porque toda bondad es atributo divino y no ser malvado, una satánica soberbia. Jesús y Judas son complementarios así como los teólogos Aureliano de Aquilea y Juan de Panonia, el ortodoxo y el hereje, el acusador y la víctima son para Dios una misma persona. El guerrero y la cautiva conforman una sola historia; el nazi Otto Dietrich zur Linde y el judío David Jerusalem, el exterminador y el exterminado, son anverso y reverso de una misma medalla. Como el buscador y el buscado, el traidor y el héroe, el soñador y el soñado, son equiparables, son reversibles, son intercambiables. Buscar es buscarse, soñar es soñarse, condenar es condenarse: ". . somos comparables al hechicero que teje un laberinto y que se ve forzado a errar en él hasta el fin de sus días o a David que juzga a un desconocido y lo condena a muerte y oye después la revelación: Tú eres aquel hombre." (Deutsches requiem)

O el individuo Droctulft fue único e insondable, como todos los individuos lo son. Pero el pensamiento humano no puede operar con extremadas y excesivas diferencias; necesita forzar los objetos para que circulen por los ejes de semejanza, para que se incorporen a los sistemas de abstracción tipificadora; necesita imponer la 
reducción binaria, ordenarlos en parejas de contrarios. Nos fuerza a alinearnos en bandos opuestos, nos resume en aristotélicos contra platónicos. Droctulft es sólo manejable como tipo genérico, como realidad esquematizada por la tradición y el olvido. Funes el memorioso, con su percepción infalible que todo lo registra y todo lo retiene, que discierne en cada objeto los mínimos detalles, las más diversas sutilezas y nada puede olvidar, es abrumado por un presente multiforme, por una heterogénea simultaneidad intolerablemente nitida, por la inconmensurable diversidad, por la infinita dispersión. Funes no puede pensar, no puede distraer, no puede tipificar, porque pensar es olvidar diferencias. Funes anula toda continuidad, incluso la que por conformismo llamamos individuo. Funes en vez de asociar, disocia; en vez de abstraer, concreta; en vez de generalizar, particulariza; en vez de universalizar, aísla; en vez de unificar, fragmenta. Funes no puede distraerse del mundo para restablecer el dominio del logos ordenador, para restaurar la sistemática conexión de causas y efectos. Funes está condenado a percibir el mundo en su realidad primordial, como una "rapsodia de voces inconexas". Y como tal, es irrepresentable, es impensable. Ninguna simbología, ningún lenguaje puede figurarlo.

El mundo no puede ser figurado por ningún símbolo genérico. Es por tanto indecible. $O$ puede ser prefigurado por una representación literal y simbólicamente ilegible, ilegible en su sentido primero y en su sentido segundo o traspuesto. La Ciudad caótica es una imagen del mundo, ininteligible, inefable. Decir la Ciudad de los Inmortales resulta tan imposible como, decir la casa de Asterion que tiene el tamaño del mundo, donde todas las partes están muchas veces, donde cualquier lugar es otro. Tan imposible como decir el éxtasis en que Tzinacán contempló la Rueda universal que estaba por doquier al mismo tiempo, donde se entretejían simultáneamente todas las cosas que fueron, que son y que serán. Tan imposible como decir el Aleph, lugar donde sin confundirse están todos los lugares del orbe, contemplados desde todos los ángulos.

La imposibilidad de este decir es múltiple: la comunicación presupone, además de un código común, una experiencia compartible; la comunicación de esta vislumbre excepcional requiere palabras aptas; esta visión es simultánea mientras que el lenguaje es sucesivo e impone la discursividad. Quedan dos recursos para expresar la infinita y simultánea heterogeneiḑad: el emblemático y el enumerativo. Al emblemático corresponden las metáforas y comparaciones empleacia; por los místicos para simbolizar la revelación en estado de trance; pero se trata de figuras analógicas contaminadas de literatura y por ende falaces. Otro problema insoluble: la enumeración, aunque parcial, de un conjunto infinito. Para sugerir la diversa infinitud del Aleph, Borges opta por una vasta enumeración caótica que yuxtapone lo distinto y distante temporal, espacial y jerárquicamente. La asociación de tamaña diversidad se asienta en un solo eje de semejanza posible: el inconmensurable, el incontable, el indescriptible universo.

La enumeración de la máxima simultaneidad, de lo extremadamente ubicuo termina con un juego de reciprocas inclusiones, porque la tierra contiene ese punto que a su vez contiene la tierra que a su vez contiene el punto; termina con la mutua inclusión de lo macrométrico en lo micrométrico y viceversa : ". . . vi el Aleph, desde 
todos los puntos, vi en el Aleph la tierra, y en la tierra otra vez el Aleph y en el Aleph la tierra, vi mi cara y mis vísceras, vi tu cara, y sentí vértigo y lloré, porque mis ojos habían visto ese objeto secreto y conjetural, cuyo nombre usurpan los hombres, pero que ningún hombre ha mirado: el inconcebible universo."

Suponiendo que pueda alcanzarse la vislumbre universal, suponiendo que se perciba lo gruesamente infinito, esa visión, si es factible, resulta inexpresable, por lo menos verbalmente. Incompatible con la mente humana, esa visión no puede ser inteligida, es incomprensible.

Especular, especulativa, espectacularmente, el hombre, una naderia accidental en la historia del universo, inventa su mundo (su versión/diversión del mundo) interpolándolo en la realidad. El mundo, para Borges, es una proyección imaginaria, una fabulación concebida según nuestra estructura intelectual, concorde con nuestras necesidades operatorias; pero la realidad es refractaria a ese molde modelado por el hombre. La sintaxis humana no concuerda con la del universo. Incompatible con la realidad, nuestro cosmos es una ficción inverificable. Para construir sus arquitecturas, la mente necesita abstraerse del universo, ampararse en la finitud que lo falsea, imponer su limitativa lectura: tlönificarse.

El cosmos, nuestra versión del impenetrable universo, adolesce de irrealidad, está inficionado de ilusión y de sofisma. Cuanto mayor la coherencia cosmológica, cuanto más perfecta su articulación, más se distancia del objeto de conocimiento y más lo distorsiona. Cuanto más univoca, menos veraz, porque la racionalidad sólo puede ejercer su omnipotencia, su metódica congruencia sin fallas cuando se aplica a un objeto desgajado de su condicionamiento material, a un objeto fictivo. No hay historia de un planeta con más rigurosa cohesión que la Tlön, porque ha sido concebida por hombres para satisfacer exigencias humanas.

La enciclopedia de Tlön es parábola o parodia de esa empresa milenaria, de ese cúmulo colectivo, progresivo: la suma del saber, la obra más vasta emprendida nunca por los hombres. Borges, el agnóstico, el escéptico, menoscaha su fundamento, impugna sus pretenciones, niega su eficacia última. Por fin, inalcanzable el universo, todo conocimiento se torna conjetural; intransitivo, no pasa del sujeto, no puede alcanzar lo objetivo; reducido a puro proceso mental, opera en circuito cerrado. En Tlön se considera toda actividad científica como mero hecho psíquico, todas las disciplinas se subordinan a la psicología. Todas ellas están compelidas a concebir el espacioso y simultáneo universo como series de procesos mentales que se suceden en el tiempo. La temporalidad mental no puede asociarse con la extensión objetiva. $O$, mejor dicho, lo espacial, dimensión de la realidad, para ser pensado, tiene que ser traspuesto a lo temporal, única dimensión del pensamiento.

Toda relación causal resulta arbitraria; es una de las tantas lecturas posibles frente a la extrema multiplicidad de fenómenos. Concatenarlos causalmente és una pura asociación de ideas, una concomitancia que vincula distintos estados del sujeto perceptor. Esta vinculación resulta siempre aluisiva porçue endilga a la realidad nexos que sólo son modalidades subjetivas de ligar singularidades independientes. Así las ciencias o la filosofía, que tienen por función producir conocimiento sobre la 


\section{ESTUDIOS}

base de relaciones causales (logicas), carecen de valor referencial y devienen construcciones imaginarias, cuyo mayor o menor atractivo residirá en el asombro que susciten. Su seducción, la adhesión que recaban son directamente proporcionales al ingenio puesto en obra. Con excepción de la psicología, la ciencia y la filosofía se adscriben a la literatura fantástica.

Borges afirma la imposibilidad de generalizar, de superar la autonomía, la especificidad de las singularidades individuales, de reducir en abstracto, por imposición racional, la disociada heterogeneidad de lo real. Afirma la imposibilidad de adicionar estados pasados con presentes o futuros. Refuta nuestras dimensiones temporales, porque el presente puntual, cambiante, carece de precisa limitación, es indefinida fugacidad; el futuro, hipotético, no tiene realidad objetiva, es sólo una esperanza presente; el pasado sólo existe en tanto se actualiza, en tanto se vuelve presente: indefinición.

El tiempo es rebatido con una argumentación lógica. Luego, en lugar de otorgarle carácter axiomático, Borges la yuxtapone a otras refutaciones cada vez más esotéricas, la confunde con otras suposiciones o permutaciones de una misma fabulación, todas conjeturales, equiparables, igualmente fantásticas, construcciones placenteras o sensacionales con las que se intenta responder a un enigma indescifrable.

Borges evidencia la imposibilidad de superar las singularidades individuales; opera con lo genérico invalidado de realidad. La irrealidad borgeana implica rechazo de la profundidad corporal, de la espesura material en su inmediata y confusa concresión. A las densas mezclas, a las acciones y pasiones entrañables, superpone sus impasibles tesis y antítesis. Remonta sus personajes por encima de las honduras mentales y viscerales, los tipifica despojándolos de espesor carnal y psicológico. Sus rasgos, sus afectos, sus procederes no los personalizan, no los identifican, son los desprovistos de excepción, son los de cualquier hombre, son los de todos, son los de ninguno. Borges sabe que los caracteres de las sustancias no compasan, compiten con los caracteres de las ideas, pero siente pavor por el caos corporal incompatible con el razonamiento. La racionalidad borgeana opera en el vacío incorporal sabiéndose manipuleo malabar, sabiendo que la naturaleza tiene otra gramática.

El universo es una criptografía definitivamente enigmática, siempre tentadora pero insoluble. La verdad inalcanzable ha sido sustituida por una exigencia interna al razonamiento, por un consenso intersubjetivo. Un código inherente a la articulación del discurso impone una restricción de los posibles y una doterminada manera de conectarlos, como si ese código fuese efecto de naturaleza, un determinismo fáctico. La verdad ha sido suplantada por una previsibilidad convencional que llamamos verosimilitud.

Historiar el universo es tan hipotético como historiar acciones humanas. Para Borges, la realidad pretérita es irrecuperable mediante la memoria que practica su propia selección, que borra y escribe según sus secretos requerimientos. Historiar es hacer verosímil una relación sobre lo sucedido, otorgarle coherencia narrativa, es 
decir someterla a los reclamos específicos de una forma literaria y así dotarla de una apariencia de verdad, tornarla convincente, montar el espectáculo de modo que provoque la sugestión, la ilusión de realidad, como si la causalidad textual fuese equiparable a la real.

La historia no existe en el nivel de los hechos, no está inscripta en lo real. La historia es una conexión ilativa que el historiador trama imponiéndola abusivamente a lo fenoménico por una necesidad que responde no a los eventos sino a nuestro modo de aprehenderlos. La historia es un artificio disfrazado de necesidad fáctica que presupone con candor una continuidad entre texto y mundo, como si lenguaje y realidad fueran equivalentes e intercambiables. Para que la historia exista hay que hilvanar con lo disperso y diverso un encadenamiento factual y transformarlo en discurso. Borges denuncia la doble desnaturalización que ambas operaciones implican: "-En Cornwall dije que era mentira la historia que te oí. Los hechos eran ciertos, o podían serlo, pero contados como tú los contaste, eran, de un modo manifiesto, mentiras." (Abenjacan el Bojarí, muerto en su laberinto) Hechos ciertos urden una historia mentirosa. Para contrarrestar la arbitrariedad (ilegibilidad, ininteligibilidad) de los hechos no concatenables en sí, para cancelar la contingencia aleatoria, se los enlaza imponiéndoles un continuo presumible, presuntuoso, prepotente.

La historia pertenece, según Borges, al género narrativo. Propone un pasado más satisfactorio que el real, una anécdota conexa para sustituir la otra difusa, incongruente, desconocida de la que ignoramos si es engañosa : “. . .ya la enseñanza de su historia armoniosa (y llena de episodios conmovedores) ha obliterado a la que presidió mi niñez; ya en las memorias un pasado ficticio ocupa el sitio de otro, del que nada sabemos con certidumbre-ni siquiera que es falso." (Tlïn, Uqbar, Orbis Tertius). Toda historia es supuesta, toda historia es figurada. Si la verdad es irrecuperable, no queda otro refugio subterfugio que urdir ficciones que se reconocen como tales, desembarazarse de las ineficaces, de las falaces restricciones de la verosimilitud realista y proponer fabulaciones que no pretendan representar correlatos objetivos, que se saben juego paradojal, permutaciones imaginarias, modus operandi, alegoría, mito, fantasmagoría, fantasioso simulacro.

La letra, más que consuelo, es condena, condena a un vano devaneo por la periferia de ese impenetrable arcano que es el conocimiento total de tan siquiera una partícula de mundo. En algún hexágono de la ilimitada Biblioteca, en algún anaquel debe haber un libro que cifre y compendie el dilatado universo; quizá sea una página, quizá una fórmula, quizá una sola palabra, quizá una sílaba, pero es inhallable e indescifrable; peor: es irreconocible, podemos pasar por ella sin saberlo. Presuntamente localizado, examinado y leído, el libro total puede resultarnos un galimatías cacofónico, porque el universo es, como ese laberinto de letras, inescrutable.

Borges dice reiteradamente su desdén por lo escrito; repite que los libros nada significan en sí, que buscarles sentido es una inveterada superstición tan vana como inquirir los sueños o las lineas de la mano. Giambattista Marino en su lecho de muerte contempla una rosa y la ve por fin en si, en su propia naturaleza que ningún 
lenguaje puede comunicar: "Marino vió la rosa, como Ádan pudo verla en el Paraíso, y sintió que ella estaba en su eternidad y no en sus palabras y que podemos mencionar o aludir pero no expresar y que los altos y soberbios volúmenes que formaban en un ángulo de la sala una penumbra de oro no eran (como su vanidad soñó) un espejo del mundo, sino una cosa más agregada al mundo." (Una rosa amarilla) La abrumadora acumulación de páginas, la conciencia de que todo está escrito, intimida, anula, afantasma. Es inútil escribir. Lo atesorado por todas las bibliotecas, la biblioteca total no mitiga el divino desorden, no consigue justificar el confuso universo, no explica ese absurdo que parece obra de dioses enloquecidos.

En Borges no hay idolatría por el libro ni exaltación de la escritura. Máxima conciencia de sus alcances, consumado dominio de sus recursos no deben confundirse con fetichismo literario. Sus textos están signados por la mesura, por la restricción formal, por el equilibrio entre continuidad y discontinuidad, entre expansión y retracción, entre permanencia y cambio. El medio lingüístico nunca es liberado a su propia energía, nunca desembarazado de su sumisión al mensaje. El discurso nunca se independiza de la historia. Borges raramente pone de manifesto la especificidad material de su producción significativa. No busca la novedad, más bien la denigra; en su escritura comanda lo previsible.

La escritura borgeana se asiente en una rigurosa coherencia, en una sintaxis severamente controlada, en una conténción léxica, en un principio de economía tendiente a evitar el gasto superfluo, a descartar todo derroche. La escritura de Borges es funcional y unitiva. La escritura de Borges es una de sus paradojas. La coherencia dada por la prosa simétrica y precisa, por la estricta articulación conceptual, por la verosimilitud sintáctica no es sino un efecto en superficie, una parodia de rigor para ocultar la inseguridad semántica, la perturbación epistemológica que nos deparan sus ficciones. Entre el discurso de Borges y sus historias hay una brecha equiparable a la que existe entre la ciudad terrestre y la celeste, entre cosmos y caos.

Si aguzamos el análisis, también e,\} la escritura encontraremos los índices equívocos, los sembradores de ambigiiedad, las fisuras del aparente continuo: paréntesis perturbadores, inciertos puntos suspensivos, adjetivos antitéticos, inserciones desorientadoras, términos amfibológicos, disyunciones desconcertantes; encontraremos por doquier las señales del desasosiego semántico.

Todo en Borges alude a la invalidación de nuestras pautas cognoscitivas, de nuestros principios de razón suficiente, de nuestra protectora univocidad, de nuestros tranquilizantes significativos. Borges remueve los cimientos de toda intelección realista; desbarajusta el sistema de coordenadas que permiten formular postulaciones sobre la realidad, desbarata las categorías clasificatorias, embarulla la causalidad convenida. Con tácticas múltiples y en toda dirección, dispara su artillería paradójica para relativizar las estrategias del conocimiento. Más que ofensivas frontales, las suyas son acciones de solapada zapa, sibilino desgaste, profusión de focos subversivos. Gnoseológicamente, poco o nada queda firme frente a su agnosticismo, frente a su escepticismo omnicomprensivos. Queda, sin embargo, un un saldo favorable: la incontestable validez de sus escritos. 
Otra paradoja • Brrges an:ala el principio de identidad; niega la originalidad, niega que algo de !u mucho escrito pueda considerarse patrimonio individual de un autor. Vislumbra su obra, igual que cualquier producción literaria, como una de las tantas encrucijadas posibles, como uno de los múltiples entrecruzamientos de textos precedentes y presentes, como un momento de coexistencia, como una parcela de la innumerable coextensividad textual. Pero su escritura es su identificadora, la que singularizada lo singulariza. Sus personales fabulaciones, su especial entramado fictivo, su ilación, su ideación, sus mixturas, sus montajes nos permiten identificarlo, identificar por lo menos al otro Borges, el Borges público, el de las páginas válidas, aquél que pasó de las mitologías del arrabal a los juegos con el tiempo y con lo infinito. Esos juegos ya son de Borges y de ellos no quiero librarme.

University of Paris

Saul Yurkievich 